Elhassan, E. E. M., M. Sládeček, S. Badaam, K. Brynychová, P. Chajma, V. Firlová, V. Janatová, V. Kubelka, L. Pešková, E. Vozabulová, A. Almuhery, and M. Śálek. 2021. An artificial lakes system intended for human recreation supports a vital breeding population of Red-wattled Lapwing in the Arabian Desert. Avian Conservation and Ecology 16(2):20. https://doi.org/10.5751/ACE-01978-160220

Copyright (C) 2021 by the author(s). Published here under license by the Resilience Alliance.

Research Paper

\title{
An artificial lakes system intended for human recreation supports a vital breeding population of Red-wattled Lapwing in the Arabian Desert
}

\author{
Esmat E. M. Elhassan ${ }^{1,2}$ (D), Martin Sládeček ${ }^{2}$, Saoud Badaam ${ }^{1}$, Kateřina Brynychová ${ }^{2}$, Petr Chajma ${ }^{2}$, Veronika Firlová ${ }^{2}$, Veronika $^{3}$ \\ Janatová ${ }^{2}$, Vojtěch Kubelka ${ }^{3,4,5,6}$, Lucie Pešková $^{2}$, Eva Vozabulová ${ }^{2}$, Aisha Almuhery ${ }^{1}$ and Miroslav Śálek ${ }^{2}$ \\ ${ }^{1}$ Natural Resources Conservation Section, Environment Department, Dubai Municipality, Abu Hail, Dubai, United Arab Emirates, \\ ${ }^{2}$ Faculty of Environmental Sciences, Czech University of Life Sciences Prague, Kamýcka 129, 16000 Prague, Czech Republic, \\ ${ }^{3}$ Department of Animal and Plant Sciences, University of Sheffield, Alfred Denny Building, Western Bank, Sheffield S10 2TN, \\ United Kingdom, ${ }^{4}$ Department of Biology and Biochemistry, University of Bath, Claverton Down, Bath BA27AY, United \\ Kingdom, ${ }^{5}$ Department of Biodiversity Research, Global Change Research Institute, Czech Academy of Sciences, Bělidla 4a, Brno, \\ 603 00, Czech Republic, ${ }^{6}$ Department of Evolutionary Zoology and Human Biology, University of Debrecen, Egyetemtér 1,
}

H-4032, Debrecen, Hungary

\begin{abstract}
Various animal species worldwide use artificial environments for reproduction, a suitable alternative to dwindling native habitats. An artificial lake system established in the core zone of the Al Marmoom Desert Conservation Reserve, Dubai, United Arab Emirates, primarily intended for recreational purposes, assists wildlife to cope with water shortages and the extreme hot climate of the Arabian Desert. This area potentially opens up conflicts between recreational use and wildlife welfare. The Red-wattled Lapwing (Vanellus indicus aigneri) is a spreading Asian shorebird tightly linked to water resources and tolerant of human disturbance. We analyzed the habitat use and reproductive success of this species, following 361 nests and 373 chicks in 2018 and 2019 to reveal the breeding potential of the Reserve. The occurrence of lapwings dropped sharply at a distance of $500 \mathrm{~m}$ from the lakes, regardless of vegetation cover and desert type. In addition, nest site choice strongly reflected the proximity of water within the core lakes area. The Lapwings bred preferentially on islands built in the centers of the lakes, where they started breeding earlier in the season. They had a lower nest predation rate on islands than on the surrounding mainland, but the chicks grew slightly more slowly on islands, probably due to lower food availability. However, survival of island and mainland chicks was similar. We conclude that the shallow shores of lakes with islands make the area suitable for breeding of the Lapwing in the Arabian desert, despite extensive recreational use and constant human disturbance. This study shows an example of combining appropriate landscape design with benefits for humans and current support for wildlife conservation.
\end{abstract}

\section{Un réseau de lacs artificiels destiné à la recréation d'un habitat par l'homme soutient une population vitale de reproduction de vanneaux indiens dans le désert d'Arabie}

RÉSUMÉ. Différentes espèces animales à travers le monde se reproduisent dans des environnements artificiels, qui constituent une alternative adéquate à leurs habitats d'origine en déclin. Un réseau de lacs artificiels créé en plein coeur de la Réserve de conservation du désert d'Al Marmoom, à Dubai, aux Émirats Arabes Unis, principalement destiné à des activités de loisirs, aide la faune sauvage à gérer la sécheresse et les températures extrêmes qui règnent dans le désert d'Arabie. Cette zone pourrait éventuellement donner lieu à des conflits entre l'usage récréatif des terres et le bien-être de la faune. Le vanneau indien (Vanellus indicus aigneri) est un oiseau de rivage asiatique dont la population se propage et est étroitement liée aux ressources en eau et à sa tolérance des perturbations humaines. Nous avons analysé l'utilisation de l'habitat et le succès reproductif de cette espèce, en observant 361 nids et 373 oisillons en 2018 et 2019 afin de mettre en évidence le potentiel reproducteur de la réserve. La population de vanneaux déclinait considérablement à une distance de $500 \mathrm{~m}$ des lacs et ce, quels que soient la couverture végétale et le type de désert. En outre, le choix du site des nids reflétait fortement la proximité d'eau dans la zone centrale des lacs. Les vanneaux se reproduisaient de préférence sur des îles artificielles aménagées au centre des lacs, où leur saison de reproduction débutait plus tôt. Ils étaient confrontés à un taux de prédation des nids moindre sur les îles que sur les terres environnantes, mais les oisillons se développaient légèrement plus lentement sur les îles, probablement en raison d'une nourriture plus rare. Toutefois, la survie des oisillons sur les îles et sur le continent était similaire. Nous en concluons que les rives peu profondes des lacs abritant des îles favorisent la reproduction du vanneau dans le désert d'Arabie, en dépit d'une utilisation récréative intensive et de perturbations humaines constantes. Cette étude présente un exemple de combinaison d'une conception paysagère appropriée présentant des avantages pour les humains et du soutien actuel de la conservation de la faune.

Key Words: chick survival; habitat selection; nest predation; population dynamics; Red-wattled Lapwing; shorebirds; wetland conservation 


\section{INTRODUCTION}

Pressure of human activities on biodiversity is accelerating globally, from wildlife disturbance, through direct persecution, to extensive habitat destruction (Almond et al. 2020). Freshwater wetland habitats are among the most affected, with many rapidly declining species (Delany et al. 2009, Roodbergen et al. 2012, Munro 2017, Studds et al. 2017, Amano et al. 2018). Great efforts have been made to protect the remaining wetlands and to create new opportunities for waterbirds (Amano et al. 2018). Natural or semi-natural environments in many areas worldwide are being transformed into recreational zones for people. The emergence of new habitats of this type may attract native species, whose populations begin to thrive owing to the new environment (e.g., Campbell and Smiles 2019). However, it is uncommon that unique habitats for wetland vertebrates requiring a permanent water resources are created in the midst of a desert and that these species naturally establish successful populations there. Ma et al. (2010) thoroughly reviewed the literature and identified several generalizable features for determining the biodiversity of artificial wetlands. However, none of the reviewed studies was performed in a newly established freshwater wetland embedded in a desert ecosystem. In addition, most of the reviewed studies were based on population abundances. However, high abundance without knowledge of reproductive success may not reflect the quality of the site and its potential for long-term species persistence (van Horne 1983). It is worthwhile exploring the reproductive success of birds that use artificial wetland habitats within desert recreation zones to reveal potential conflicts between breeding birds and public visitors. A detailed insight into reproductive success can lead to greatly improved site management by finding ways to combine conservation requirements with recreational potential (Hartman and Oring 2009, McIntyre and Heath, 2011, Saalfeld et al. 2013, Specht et al. 2020). Examples of wetland species naturally settled and benefiting from new habitats in a desert environment can inspire similar projects in the context of a globally changing climate threatened by extensive desertification of the subtropics and tropics (Andersson et al. 2011, Spinoni et al. 2015, Jackson and Prince 2016).

Shorebirds are a widespread group of waterbirds, strongly linked to wetlands (del Hoyo et al. 1996). Populations of many shorebirds are declining, and increasing numbers of studies have called for conservation for their breeding areas (e.g., Zöckler et al. 2003, BirdLife International 2009). Lapwings of the genus Vanellus are ground-breeding, plover-like shorebirds whose precocial chicks leave the nest after hatching and start foraging by themselves, relying on their patrolling parents to warn about predators, warm the chicks through the first few days of life, and lead them to food and water (Kalsi and Khera 1986). The RedWattled Lapwing (Vanellus indicus) is a widely distributed but poorly studied native Asian species that breeds in the subtropics and tropics, including Arabia. It has flexible habitat demands but requires permanent water availability (del Hoyo et al. 1996). In India, it is known for frequently nesting in agricultural landscapes and near to human settlements, where the nests have been found even on the roofs of houses (Baumann 2006, Narwade et al. 2010, 2011). Its Asian population is estimated at more than 200,000 individuals (Wiersma and Kirwan 2020). The species was considered rare in Arabia in the late 1970s (Stewart-Smith 1977) but it expanded westward as suitable habitats were created
(Campbell and Pedersen 2011). Birdwatchers' reports across Arabia showed its rapid spread, with 12,288 observations from United Arab Emirates (UAE) alone and new records from Bahrain (eBird 2021). The breeding population in the UAE is estimated at 1,000-4,000 mature individuals (Burfield et al. 2021). However, no study has assessed the habitat use of this species in the Arabian desert ecosystems. In particular, it is not clear whether and how the artificial and newly established wetland habitats can provide successful breeding opportunities for lapwings or other shorebird species.

The new artificial lake system in Al Marmoom Reserve in Dubai Emirate was established for recreation purposes and has a potential for breeding water-dependent birds, including lapwings (Dubai Municipality 2019a). Analyses of breeding habitat and reproductive success in particular habitats may indicate qualities of these habitats and their conservation value, as being documented for other shorebirds in wetlands (e.g., Thyen and Exo 2005, Toral and Figuerola 2012, Laidlaw et al. 2017) and in artificially managed landscapes (Hartman and Oring 2009, Laidlaw et al. 2017, Sharps et al. 2017). Habitat selection theory predicts that birds select nesting sites that maximize individual fitness (Hildén 1965), reduce predation and disturbance, support a favorable microclimate, and are close to food and water resources for adults and for the young (Hildén 1965, Martin and Roper 1988, Clark and Shutler 1999, Smith et al. 2007). Some or all of these requirements must be met in order to establish longterm sustainable populations.

In this study, we analyzed the population size, nesting habitats, and reproductive success in the Red-wattled Lapwing (henceforth referred to as "lapwing") breeding population that inhabits an artificially created system of freshwater lakes in an originally pristine Arabian desert. First, based on survey of occurrence, we described the importance of the proximity of water for the lapwing in the desert landscape. Second, we focused on habitat preferences, including nest distance to water and roads, and on the importance of small islands, intentionally created in most of the lakes. Islands are known as safe breeding habitats for temperate-zone ground-nesting shorebirds due to the isolation from mammalian predators (Köster et al. 2001, Büttger et al. 2006). Islands may also be more advantageous due to limited disturbance by human visitors, where lower predation may be due to lower disturbance of breeding birds (Rodrigues et al. 2018, McGrady et al. 2019). However, these hypotheses are yet to be tested in the subtropics. Therefore, and third, we monitored nests and chicks to test whether small lake islands are preferred by lapwings, if the birds breed here earlier than on the mainland, and whether the islands offer a safer habitat for more successful nesting and better chick survival. Islands could also offer more productive habitat for faster chick growth than the mainland, which is more exposed to predators from the surrounding landscape and is burdened by traffic and visitor disturbance.

\section{MATERIAL AND METHODS}

\section{Study Area}

The study area $\left(6.63 \mathrm{~km}^{2}\right)$ is situated in the core zone of the $\mathrm{Al}$ Marmoom Desert Conservation Reserve (hereinafter "Reserve"), Dubai Emirate $\left(24^{\circ} 50^{\prime} \mathrm{N}, 55^{\circ} 21^{\prime} \mathrm{E}\right)$, about $20 \mathrm{~km}$ from the nearest built-up area of Dubai. It includes 26 lakes in line formations with 
surrounding desert habitats and artificial plantations (Fig. 1). The Reserve is Dubai's largest protected area, covering an area of 950 $\mathrm{km}^{2}$ in the Seih Alsalam desert (Dubai Municipality 2017). Freshwater lakes are replenished with desalinated seawater, pumped inland from the Arabian Gulf (Dubai Municipality 2018). There are relatively dense tree plantations dominated by Ghaf (Prosopis cineraria) trees and several acacia (Acacia spp.) species to provide shade for wildlife and visitors. In some places, there are reed (Phragmites australis) beds along the coasts. The plantations and reeds are irrigated and regularly managed.

Fig. 1. Map of the study area (red line) within Al Marmoom Desert Conservation Reserve (top right corner) in Dubai in United Arab Emirates (top left corner). Lakes and islands are highlighted.

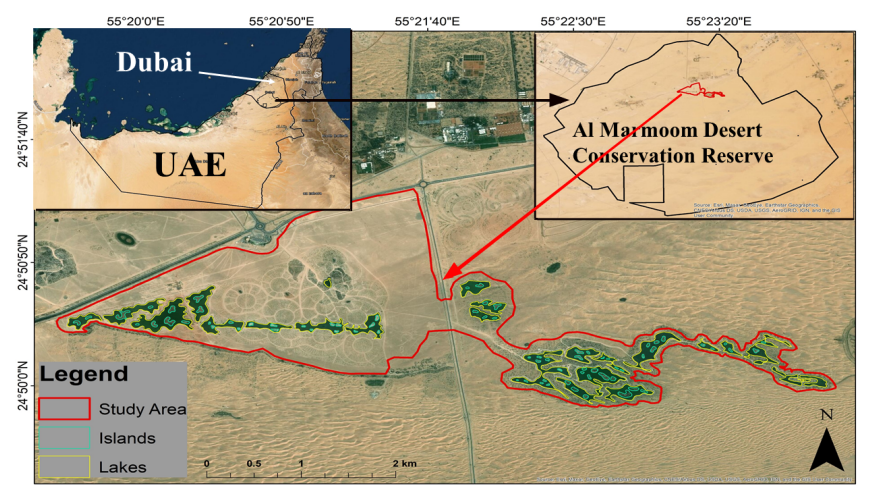

The local desert climate is characterized by mild winters and very hot summers, with the mean humidity around $60 \%$ (between $50 \%$ in May and $65 \%$ in January and February). The UAE monthly mean temperatures vary between $19^{\circ} \mathrm{C}$ (January) and $36^{\circ} \mathrm{C}$ (August) (Komuscu 2017). Between April and September, the daytime temperatures range from $38^{\circ} \mathrm{C}$ to $42^{\circ} \mathrm{C}$ (the hottest days reached $50^{\circ} \mathrm{C}$ ). The recreation pressure is high, particularly in winter (November to March), when more than 3,000 visitors visit the lakes daily at the weekends, and 1,000 visitors on weekdays. Hot summer days (May to August) attract the least numbers of visitors (up to 300 per day). People are concentrated mainly along the coastline. Entry to the islands is not allowed as per regulations (Dubai Municipality 2019b).

\section{Data Collection}

The study was conducted during two successive breeding seasons from February to August of 2018 and 2019. To determine the distribution of the lapwings on a landscape scale regarding distance to a water, desert type, and vegetation cover, we located 55 survey points with an observational radius of $150 \mathrm{~m}$ across the area of the Reserve, using GPS and a satellite map (Google Earth, https://earth.google.com). Because the close connection of the lapwings to the water has been previously described (Kalsi and Khera 1986, del Hoyo et al. 1996), we applied a stratified random method to locate half of the survey points $(n=28)$ within $500 \mathrm{~m}$ from boundary of the core study area with lakes, and the remaining half of the survey points outside this area (Fig. 2). We were interested in a threshold distance that would determine how far from water the lapwings would nest in this desert environment. We avoided the exclusive areas of large sand dunes, which are unsuitable for lapwings (Kalsi and Khera 1986). The minimum nearest distance between two neighboring survey points was set to be at least $300 \mathrm{~m}$. Each survey point was visited only once at the beginning of the season (March). After a thorough examination of the surroundings of the survey point within $5 \mathrm{~min}$, the vegetation cover $(\%)$ and the proportion $(\%)$ of gravel plains vs. sand dunes were evaluated directly in the field. The distance from the nearest lake was measured from the satellite map. All other research activities performed for this study had been situated in the core part of the study area (marked red line in Fig. 1), including the lakes system and surrounding habitats.

Fig. 2. Probability of presence of the Red-wattled Lapwing according to distance from the nearest water lagoon. The circles represent the presence (dark gray), or absence (white) on survey points at a particular distance from the nearest water lagoon. Data are fitted by the binomial glm ("glm" function; logit link function). Curve with shaded areas indicates the model prediction with $95 \%$ credible intervals based on the joint posterior distribution of 5,000 simulated values based on the model output (Table 1) and generated by the "sim" function in R (Gelman and Hill 2007). The semilogarithmic scale provides better resolution at distances up to the cut-off distance of 1,000 $\mathrm{m}$, which also includes all records of lapwings on survey points.

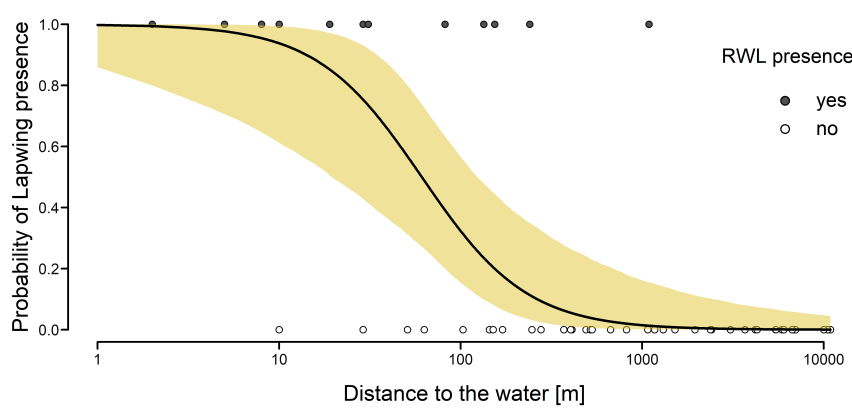

The estimation of total population size in the core area was based on two complete censuses from 20-22 March and from 5-6 June 2019. The core area was carefully surveyed using binoculars from a car with a good overview without disturbing the birds. All recorded adults were counted, and color-ringed adults (see below) were individually identified (Append. 1). We captured adult birds on the nest using spring traps. Captured birds were individually marked using metal rings and a unique combination of four color rings. During the study, we captured 196 adults (92 in 2018 and 104 in 2019).

Nests were searched by slow driving by car and through visual scanning, searching for incubating parents. The Red-wattled lapwings in the area select nest sites on open ground without vegetation or with sparse herb or shrub vegetation, and nests are thus readily visible from long distances (cf. Appends. 2, 3 for additional supporting information). Given the frequency of our visits, visibility of incubating parents, and dense tangle of roads 
throughout all the area, we assume that we found nearly all nests within the study area. The start of incubation and hatching dates were estimated by laying date (for clutches found during laying) or by the flotation test (van Paassen et al. 1984) with a presumed incubation period of $30 \mathrm{~d}$ (mean $\pm 2.2 \mathrm{sd}$; own unpublished data, $n=13$ clutches) for clutches found complete.

We divided the habitat mosaic within the study area (Brown and Böer 2004) to five main habitats (lakes, islands, plantations, sand dunes, and gravel plains) in order to specify the nesting habitat requirements of the target species. Hereafter, we referred to all terrestrial habitats except islands as "mainland."

In order to assess the nest fate, we visited each nest at 3-5 d intervals until hatching. The fate of the clutch was assigned to one of the following categories: "hatched" (at least one egg hatched), "depredated" (the eggs were known to have been depredated by the disappearance of the eggs before the expected date of hatching, or by signs such as remnants of eggshells around the nest), "failed for other reasons" (no egg hatched because the eggs were infertile or the embryos had died and/or the parents had deserted the nest), or "unknown."

We ringed 373 chicks (160 in 2018 and 213 in 2019) from 144 known nests ( 65 in 2018 and 79 in 2019), i.e., only chicks associated with particular nests are mentioned here. We aimed to recapture the chicks at approximately 1-week intervals when possible. After recapture, we weighed the chicks to the nearest $0.1 \mathrm{~g}$ using a digital balance, and we measured the head, bill, and tarsus ("HL," " BNprox," and "Tar1," respectively, according to Eck et al. 2011), with vernier calipers (all to the nearest $0.1 \mathrm{~mm}$ ).

\section{Analysis}

General linear models $(\mathrm{lm})$ were fitted using the " $1 \mathrm{~m}$ " function using R v. 4.0.2. (R Core Team 2020), generalized linear models (glm) using the "glm" function (R Core Team 2020), mixed-effects models (glmm) with the "lmer" or "glmer" functions from the "lme4" R library (Bates et al. 2015). For all model-based parameter estimates, we report the effect sizes as the median and the Bayesian $95 \%$ credible interval $(95 \% \mathrm{CI})$, based on the posterior distribution of 5,000 values simulated by the "sim" function from the "arm" R library (Gelman and Hill 2007, Gelman et al. 2016).

To describe the distribution of lapwings on a landscape scale, we fitted glm with logit link function and binary response (present/ absent around a survey point). Distance from the nearest lake and proportion of vegetation and gravel plains in a $150-\mathrm{m}$ radius around the survey point were used as predictors. In order to meet distribution requirements, we ln-transformed the distance from the nearest lake.

To estimate the population size, we used data from complete censuses of adults across the area in March and June 2019. We applied a Capture-Mark-Recapture approach (Krebs 1999) based on expectation of equality between the proportion of marked adults from total population and the proportion of marked adults recorded during census from the total number of color-marked adults. In addition, to reduce overestimating by repeated recordings of the same individuals during a census, we multiplied the total counts during census by the proportion of uniquely identified adults from all records of marked adults (which includes repeated records) during the census (see Append. 1 for input values and calculation).

In order to test preferences in breeding site selection in the core study area, we performed 1,000 simulation runs. As there can be a seasonal pattern in breeding site preferences and because the number of simulated nests can influence the simulation process, we ran simulations separately for the beginnings of March, May, and July (i.e., the start, the middle, and the end of the breeding season). During each run, we generated random positions of the number of active nests within the specified period (the mean for the 2 years of the study). We set the minimum distance between any two random nests to $50 \mathrm{~m}$ (similar to the minimum observed distance between two neighboring active nests; personal observations) and avoided roads and lakes in placement of random nests. Without any other constraints, we simulated the preference for nest placement in close vicinity of the lakes. Because there was an obvious and very strong preference for breeding close to the lakes, we changed the random point selection process for exploring preference/avoidance of the remaining nest-site characteristics as follows. Using the density R function, Gaussian kernel, and bandwidth of 0.2 , we estimated the kernel density function of the distribution of ln-transformed distances of truenest locations to the nearest lake. Then we sampled random positions with probability weights equal to the kernel density in the particular distance from the lake. During each such simulation run, we calculated the median distances to the nearest road, and the proportion of the nests that were located on islands, in plantations, sand dunes, and gravel plains (Fig. 3). Subsequently, these metrics were compared with those calculated from locations of real nests. The distances from the nearest road were calculated only for nests (real or simulated) that were not placed on islands. Finally, the $P$ values were calculated as the proportion of simulated estimates (i.e., medians and proportions) that were more deviated (upward or downward) from overall simulated median than their measured counterparts.

The daily nest survival rates (DSR) were estimated using Mayfield method formulation (Mayfield 1975) as a logistic regression model with logit link function, in which success or failure was modeled with exposure period (days) as the binomial denominator (Aebischer 1999). In order to distinguish failure rate caused by predation and by other causes, we fitted two separated models. In the former model, the DSR was modeled as 1-daily predation rate (DPR), i.e., only the predation event was considered to be a failure, whereas all nests that were not depredated were considered as successful. In the latter model, DSR was modeled as a 1-daily failure rate (DFR), i.e., all failures were taken into account, and only hatched nests were considered to be successful. The exposure period included the period from the date on which the nest was found until the hatch date (with $30 \mathrm{~d}$ of expected incubation; Kumar et al. 2020). The exposure period of unsuccessful nesting attempts reflected the exact termination date (if known) or halfway period between the last visit to an active nest and the next negative visit. Hatching success (i.e., total survival rate; TSR) was calculated as the DSR (from any of the models), powered by the incubation time, i.e., $30 \mathrm{~d}$. As predictors of nest survival, we used the placement of the nest (island/mainland) and the year, including the interaction. 
Fig. 3. Distribution of lapwing nests within the core study area in 2018 and 2019, including the five main divisions of the habitat in the territory. Red points show the positions of all known nests in a particular year ( $n=187$ and 174 nests, for 2018 and 2019, respectively). The pie charts show the proportion of nests identified in the particular year and habitat, respectively.
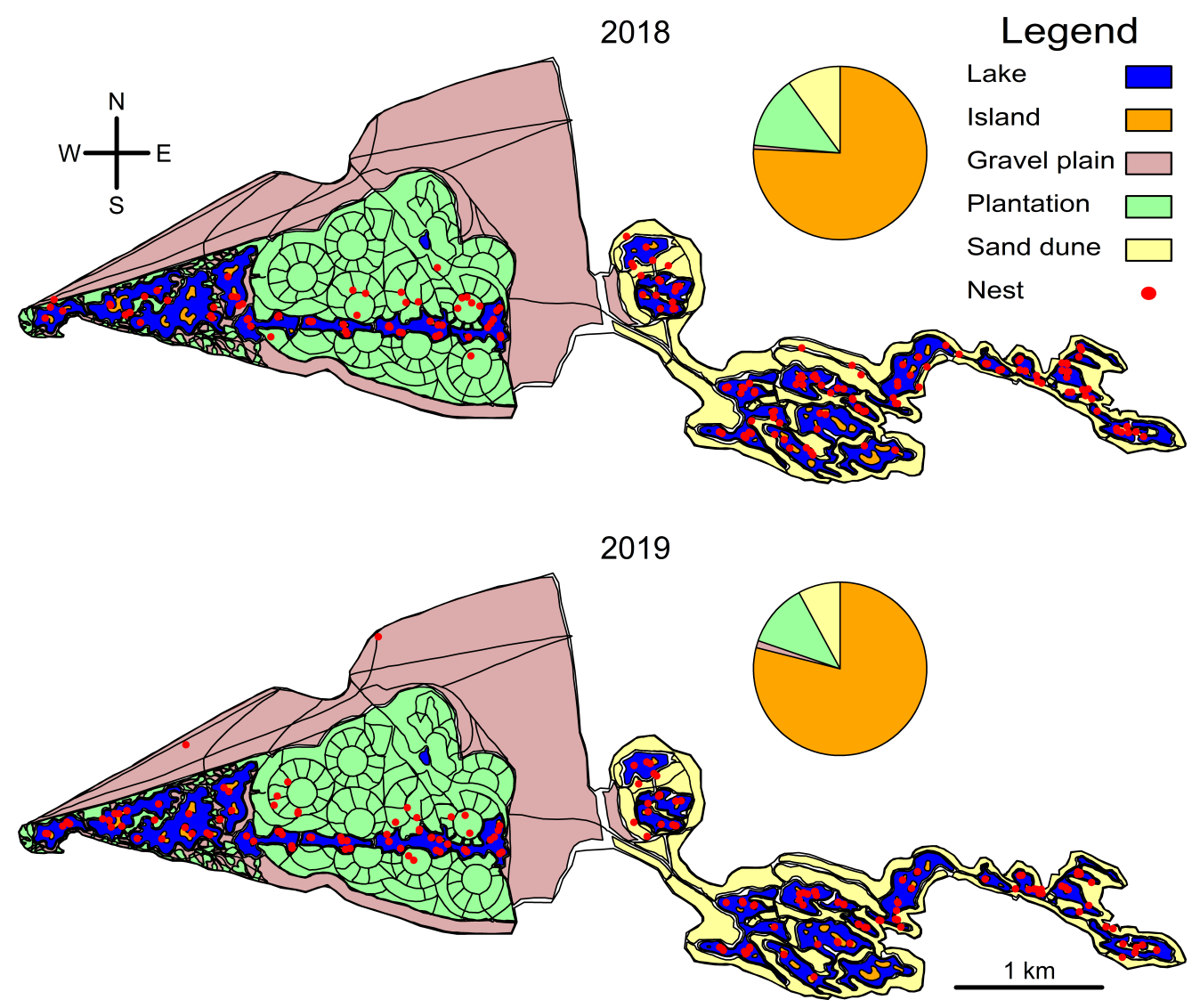

To describe the growth and the body condition of the chicks, we fitted two gaussian glmm, i.e., a "growth" model and a "body condition" model. In the "growth" model, we used body mass as a response variable and as a proxy for growth. In order to approach homoscedasticity and independence of the model residuals, we ln-transformed the body mass. As a response variable in the "body condition" model, we used residuals from the linear regression model with the third-root of the body mass as a response variable and the head length as a predictor. In both models, we used the age of the chick in days, the placement of the nest (island/mainland), and the year as predictors, and we also included two interactions between age and nest placement and between age and year. As many chicks were measured several times, we used chick identity nested in family identity as random intercepts.

To describe the differences in chick survival, we estimated the hazard function from the multilevel discrete-time survival model with a logit link function (i.e., the logit frailty model; see Hox et al. 2018) and death ( 0 - alive; 1 - dead $)$ as a response. Because the detectability of the chicks steeply decreased before fledging, we right censored the data on the 35th day of chick's life (i.e., several days before fledging, which is expected around 38th day of life; del Hoyo et al. 1996). As we failed to ensure the exact day of a chick's recapture and because a failed search for a particular chick does not necessarily mean a dead chick, we stated the chick death arbitrarily $1 \mathrm{~d}$ after its last record alive. Although this approach certainly leads to general overestimation of the hazard rate, it enabled us to compare the hazard rates between the chicks from island and mainland nests, which was the main purpose of the corresponding analysis. The postulation of death $1 \mathrm{~d}$ after the last positive record is based on these considerations: (1) the chicks were unlikely to emigrate before fledging as the study area is well isolated by a dry desert from other suitable habitats in the surrounding landscape where a shift of unfledged chicks is highly unlikely; (2) the lapwing families are heavily dependent on the proximity to water, and parents usually stayed close to their nesting territory throughout the season (usually on one island and/or in nearby mainland). Specifically, we never observed unfledged chicks more than $300 \mathrm{~m}$ from the nest. Similarly to the daily nest survival models, we used placement of the nest (mainland/island) and the year, including the interaction, as predictors, and the nest identity as a random intercept.

\section{RESULTS}

The distribution of adult lapwings over the landscape clearly demonstrated the need for water nearby, but the amount of 
vegetation cover and gravel plains of the desert were unimportant in describing lapwing occurrence (Table 1). The distance between the survey points and the nearest water varied between $2 \mathrm{~m}$ and $10,900 \mathrm{~m}$ (median $518 \mathrm{~m}$, mean 2,292 m), and although no lapwings were present at some survey points in the immediate vicinity of lakes, most of the lapwings were concentrated within $500 \mathrm{~m}$ from the lakes. Conversely, no lapwings have ever been recorded more than $1,000 \mathrm{~m}$ from the lakes (Fig. 2).

Table 1. Effects of the distance to the nearest lakes and the vegetation cover on presence of the Red-wattled Lapwing. The posterior estimates (medians) of the effect sizes with $95 \%$ credible intervals (CI) from a posterior distribution of 5,000 simulated values generated by the "sim" function in R (Gelman et al. 2016). The variance components were estimated by the "glm" function with the binomial family and logit link function. The response variable was the presence (1), or the absence (0) of Lapwings up to $150 \mathrm{~m}$ from the counting point $(n=55)$. The vegetation cover and gravel cover were estimated within the same radius. The distance to water (in meters) was 1 -transformed. Estimates with 95\% CI not containing 0 are statistically significant.

\begin{tabular}{lllrrr}
\hline \hline \multirow{2}{*}{ Response } & $\begin{array}{l}\text { Effect } \\
\text { type }\end{array}$ & \multicolumn{3}{c}{$95 \%$ CI } \\
\cline { 2 - 5 } & Estimate & Lower & Upper \\
Presence of & Fixed & Intercept & 4.076 & 0.363 & 7.714 \\
Lapwings & & & & \\
& & $\begin{array}{l}\text { Vegetation cover (\%) } \\
\text { Gravel cover (\%) }\end{array}$ & 0.02 & -0.036 & 0.079 \\
& $\begin{array}{l}\text { Distance to water (m; ln } \\
\text { transformed) }\end{array}$ & -1.488 & -2.469 & -0.523 \\
& & & & \\
\hline
\end{tabular}

We estimated the total population size in the study area (Fig. 1) at ca. 245 adult individuals (244 in March and 247 in June 2019; Append. 1). However, a high proportion of the population in each part of the season represented non-breeding individuals.

The breeding season lasted from late January to late August (Append. 4). The earliest nest was found on 31 January 2019 with four eggs, with laying starting on 24 January, and the last nest was hatched on 27 August 2019. After a slow start in early February, we observed peak incubation in April and May. The rate of nest initiation then slowed down again from late June to mid-August. The pairs started to breed earlier on the islands than on the mainland (both years pooled median on islands 6 April, median on the mainland 22 April; Mann-Whitney test, $P=0.001$; Append. 4)).

We found 361 nests (187 and 174 in 2018 and 2019, respectively). Lapwings placed their nests preferentially close to the water (Figs. $3,4)$; the median distance to the nearest water was $5 \mathrm{~m}$, compared with $210 \mathrm{~m}$ in randomly simulated points (median of simulated medians, all $P<0.001)$. However, 18 nests $(5 \%)$ were further than $100 \mathrm{~m}$ from the nearest lake, with a maximum of $822 \mathrm{~m}$. In addition, we found a strong preference for breeding on islands, even after control for the distance to the lake (see methods). Overall, $63 \%$ of the nests were situated on islands, compared with ca. $30 \%$ of randomly simulated nests (median, all $P<0.001$, except of July 2019 where $P=0.41$; Fig. 4). Also, the real nests located on islands had a shorter distance to water (mean \pm s.e., $2.83 \pm 0.26$ $\mathrm{m})$ compared with nests located on the mainland $(18.85 \pm 3.28$ $\mathrm{m})$. Interestingly, we found only a weak avoidance of nesting nearby the roads, when the median distance to the nearest road for real nests not located on islands was only $3.6 \mathrm{~m}$ longer than the simulated median ( 7.4 vs. $3.7 \mathrm{~m} ; P<0.001-0.52$; note that the highly deviated median from March 2019 is based on only two nests, as all other nests on that date were situated on islands; Fig. 4). We found no clear preference or avoidance for breeding in plantations $(10 \%$ of real nests vs. $6 \%$ of simulated nests after control for the distance from the water-see Methods; $P$ 0.0010.7; Fig. 4), on sand dunes ( $7 \%$ vs. $12 \%, P 0.08-0.35$; Fig. 4 ), and on gravel plains $(0.7 \%$ vs. $1.2 \%, P 0.1-1$; Fig. 4$)$.

Fig. 4. Median distances of lapwing nests from water and roads and their proportions in various habitats for the middle of the season (May 2018 and 2019). Boxplots represent the distributions of the medians obtained by running 1,000 random simulations (for details see Methods) and depict the median (horizontal line inside the box), the 25 th to 75 th percentiles (box), the 25th and 75th percentiles minus or plus the $1.5 \times$ interquartile range, respectively, or the minimum and maximum value, whichever is smaller (whiskers), and outliers (circles). Squares represent the medians or the proportions found for real nests. The summarized results represent the whole season and both years, as the differences within the season as well as between the seasons were not significant (see Append. 6).

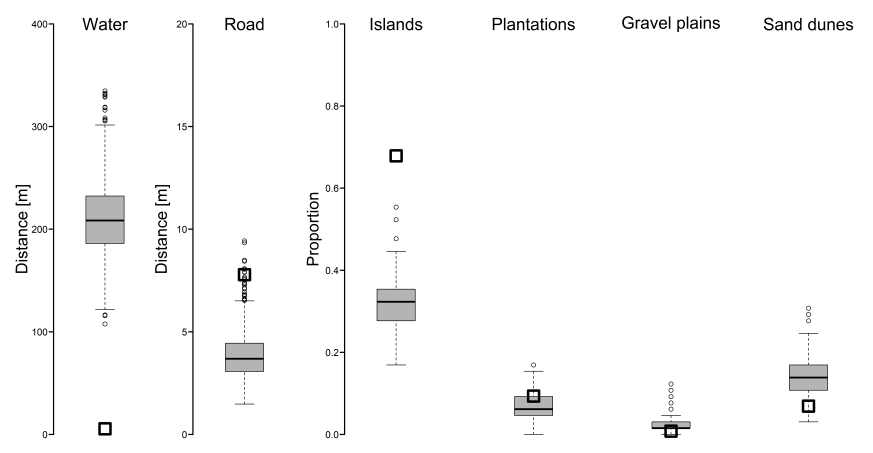

Out of 361 nests, 228 nests $(63.2 \%)$ hatched successfully, 56 nests $(15.5 \%)$ were depredated, 28 nests $(7.8 \%)$ failed for other reasons, and the fate is unknown for 49 nests (13.6\%) (Append. 5). We found significant differences between daily survival rates of nests on islands and on the mainland due to predation (Table 2a) as well as all causes of failure (Table $2 b$ ). The daily predation rate of nests placed on islands (Estimate 0.006, 95\% CI 0.004-0.01; Table 3a) was significantly (ca. four times) lower than on nests situated elsewhere on the mainland (Estimate 0.024, 95\% CI 0.018-0.033). Also, total failure rates (after adding other failure reasons) showed a similar pattern (Table $3 \mathrm{~b}$ ), indicating that predation played an important role in total failure rates.

The chicks hatched in mainland nests had a better initial condition (see the difference in intercepts; Table 4, Fig. 5a), faster growth (Table 5, Fig. 5b), but similar survival (Table 6, Fig. 5c) compared with the chicks from island nests. Generally, the patterns of chick growth were similar in the 2 years (Tables 4-6). 
Table 2. Daily nest survival rates, taking into account predation alone (A) and all causes of failure together (B), respectively. The posterior estimates (medians) of the effect sizes with $95 \%$ credible intervals (CI) from a posterior distribution of 5,000 simulated values generated by the "sim" function in R (Gelman et al. 2016). Variance components were estimated by the "glm" function with the binomial family and logit link function. Each nest was taken as a unit of analysis, and each day of nest exposure was taken as a Bernoulli trial. Estimates with $95 \%$ CI that do not contain 0 are statistically significant.

\begin{tabular}{lllrrr}
\hline \hline A & & \multicolumn{4}{c}{$95 \%$ CI } \\
\cline { 4 - 6 } Response & Effect type & Effect & Estimate & Lower & Upper \\
\hline Daily & Fixed & Intercept & 3.772 & 3.329 & 4.221 \\
survival rate & & & & & \\
& & Island & 1.592 & 0.660 & 2.521 \\
& & Year19 & -0.166 & -0.823 & 0.496 \\
B & & Island:Year19 & -0.295 & -1.458 & 0.858 \\
& & & \multicolumn{4}{c}{$95 \%$ CI } \\
\cline { 4 - 6 } Response & Effect type & Effect & Estimate & Lower & Upper \\
\hline Daily & Fixed & Intercept & 3.567 & 3.177 & 3.940 \\
survival rate & & & & & \\
& & Island & 1.276 & 0.573 & 2.004 \\
& & Year19 & -0.399 & -0.930 & 0.153 \\
& & Island:Year19 & 0.035 & -0.884 & 0.925 \\
\hline
\end{tabular}

Table 3. A summary of nest survival characteristics, considering predation alone (A) and all causes of failure together (B), respectively. Daily survival rate $=\mathrm{DSR}$; total survival rate $=\mathrm{TSR}$, taking into account a $30-\mathrm{d}$ incubation period (median, $n=13$; personal observation); daily predation rate = DPR; daily failure rate $=$ DFR, taking into account all failure causes (Mayfield 1975).

\begin{tabular}{llllllll}
\hline \hline & & \multicolumn{2}{c}{ (A) Only predation } & \multicolumn{2}{c}{ (B) All failure causes } \\
\cline { 3 - 8 } & & DSR & DPR & TSR & DSR & DFR & TSR \\
\hline 2018 & Mainland & 0.977 & 0.023 & 0.504 & 0.972 & 0.028 & 0.433 \\
& Island & 0.995 & 0.005 & 0.868 & 0.992 & 0.008 & 0.79 \\
2019 & Mainland & 0.974 & 0.026 & 0.447 & 0.96 & 0.04 & 0.292 \\
& Island & 0.993 & 0.007 & 0.799 & 0.989 & 0.011 & 0.712 \\
Pooled & Mainland & 0.976 & 0.024 & 0.479 & 0.967 & 0.033 & 0.367 \\
$2018+2019$ & Island & 0.994 & 0.006 & 0.829 & 0.99 & 0.01 & 0.741 \\
\hline
\end{tabular}

\section{DISCUSSION}

We described habitat requirements and breeding productivity of the Red-wattled Lapwing population inhabiting an artificial freshwater lakes system in the Arabian desert. The population was estimated to 245 adults between March and June 2019, with an uneven distribution across the area and the highest concentration near water. Small islands were strongly preferred for nesting, however the most disturbed places along the roads were not avoided. Lapwings bred more successfully on islands than elsewhere on the mainland, but the chicks from island nests tended to have slower growth. However, survival of island and mainland chicks was similar.
Table 4. Chick condition with respect to nest placement and year. Posterior estimates (medians) of the effect sizes with $95 \%$ credible intervals (CI) from a posterior distribution of 5,000 simulated values generated by the "sim" function in R (Gelman et al. 2016). Variance components were estimated by the "lmer" function (Bates et al. 2015). Chick identity nested to the nest identity was used as a random intercept. The relative chick condition index, taken as a residual from linear regression of the third-rooted body mass on the head with bill (for details, see Methods) was used as a response. Estimates with $95 \%$ CI that do not contain 0 are statistically significant.

\begin{tabular}{llllll}
\hline \hline \multirow{2}{*}{ Response } & Effect type & Effect & \multicolumn{3}{c}{$95 \%$ CI } \\
\cline { 4 - 6 } Condition & Fixed & Intercept & -0.021 & -0.065 & 0.023 \\
& & Age & -0.003 & -0.006 & 0.000 \\
& & Mainland & 0.078 & 0.022 & 0.137 \\
& & Year2019 & 0.015 & -0.036 & 0.064 \\
& & Age:Mainland & -0.002 & -0.006 & 0.002 \\
& Random & Age:Year2019 & 0.004 & 0.001 & 0.007 \\
& ID_chick & $0 \%$ & & \\
& (variance) & ID_nest & $29 \%$ & & \\
& & Residual & $71 \%$ & & \\
\hline
\end{tabular}

Table 5. Chick growth rate with respect to nest placement and year. The posterior estimates (medians) of the effect sizes with $95 \%$ credible intervals (CI) from a posterior distribution of 5,000 simulated values generated by the "sim" function in R (Gelman et al. 2016). The variance components were estimated by the "Imer" function (Bates et al. 2015). Chick identity nested to the nest identity was used as a random intercept. The ln-transformed weight was used as a response. Estimates with 95\% CI that do not contain 0 are statistically significant.

\begin{tabular}{lllrrr}
\hline \hline Response & Effect type & Effect & Estimate & Lower & Upper \\
\hline Weight (ln & Fixed & Intercept & 2.449 & 2.394 & 2.503 \\
transformed) & & & & & \\
& & Age & 0.039 & 0.036 & 0.042 \\
& & Mainland & -0.005 & -0.072 & 0.067 \\
& & Year2019 & 0.079 & 0.019 & 0.139 \\
& & Age:Mainland & 0.008 & 0.004 & 0.012 \\
& Age:Year2019 & 0.001 & -0.002 & 0.005 \\
& Random & ID_chick & $2 \%$ & & \\
& (variance) & ID_nest & $43 \%$ & & \\
& & Residual & $55 \%$ & & \\
\hline
\end{tabular}

\section{Habitat Use and Preferences}

We confirmed a strong relationship of the species to proximity to water, both for presence of adults in the landscape as well as nest placement. First, the probability of Lapwing presence was close to zero on survey points further than $500 \mathrm{~m}$ from a lake and, second, the median distance between nest and the nearest lakeshore was $5 \mathrm{~m}$ (Fig. 2). This shows probably a more tight dependence on water than previously found in other lapwing populations (Cramp and Simmons 1983). However, this affinity for water is not surprising in the desert environment, with midday temperatures often exceeding $50^{\circ} \mathrm{C}$. Water is important for adults 
Fig. 5. Change in relative body condition (a), growth rate (b), and survival (c) of Red-wattled Lapwing chicks in relation to age and nest placement on islands (light brown) and on the mainland (dark brown). Points $(\mathrm{a}, \mathrm{b})$ represent individual chick measurements $(n=577$ measurements of 326 chicks from 101 nests). The bars (c) represent the proportion of chicks living with certainty during the particular 5-d interval $(n=373$ chicks from 144 nests). Curves with shaded areas indicate the prediction of the model with $95 \%$ credible intervals (CI) based on the joint posterior distribution of 5,000 simulated values based on the output of the model (Tables 4, 5, and 6, respectively) and generated by the "sim" function in R (Gelman and Hill 2007). Body condition (a) was estimated as residuals from the linear regression of the third-rooted body mass on a head with a bill (for details see Methods). Body mass (b) was ln-transformed in the model but is presented back-transformed here. Estimates from the logit frailty model (c) are presented as survival curves (i.e., the model estimates were back-transformed and are presented as products).

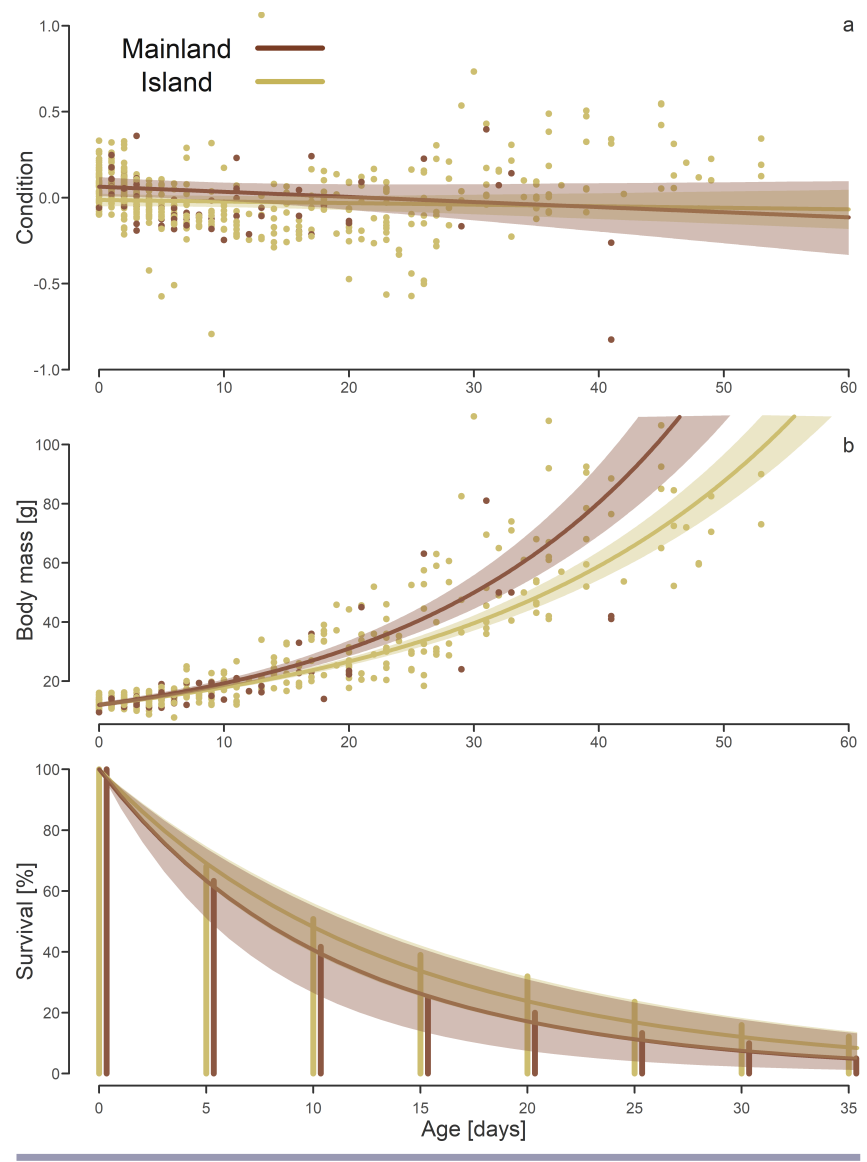

to control overheating of themselves and of their eggs (Amat and Masero 2007). Incubating adults were observed regularly visiting water for a drink and belly soaking (Kalsi and Khera 1986; personal observations). Belly soaking may be particularly important for cooling eggs in high ambient temperatures during disturbances by visitors in the recreational area. The lakes and the surrounding plantations are connected by a tangle of unpaved
Table 6. Chick survival with respect to nest placement and year. Output from the logit-frailty model; the posterior estimates (medians) of effect sizes with $95 \%$ credible intervals (CI) from a posterior distribution of 5,000 simulated values generated by the "sim" function in R (Gelman et al. 2016). The variance components were estimated by the "glmer" function (Bates et al. 2015), with a binomial family and logit-link function. Nest identity was used as a random intercept. Estimates with 95\% CI that do not contain 1 are statistically significant.

\begin{tabular}{lllllll}
\hline \hline & & & \multicolumn{3}{c}{$95 \%$ CI } \\
\cline { 4 - 6 } Response & Effect type & Effect & Estimate & Lower & Upper \\
\hline Daily & Fixed & Intercept & 2.345 & 2.066 & 2.622 \\
mortality rate & & & & & \\
& & Mainland & -0.239 & -0.782 & 0.311 \\
& & Year2019 & 0.451 & 0.096 & 0.807 \\
& & Mainland: & 0075 & -0.837 & 0.974 \\
& & Year2019 & & & \\
& Random & ID_nest & $11 \%$ & & \\
& (variance) & Residual & $89 \%$ & & \\
\hline
\end{tabular}

roads, which are heavily used by cars. The adults, pushed away from the nest for a long period of time, must deal quickly with the risk of eggs overheating.

However, several nests were further than $100 \mathrm{~m}$ from the nearest lake. These adults may have nested near the large number of small water sources like irrigation pipes distributed over all habitats to support vegetation cover and plantations. Individual birds or pairs can then reside around these small water sources.

We also confirmed a strong preference by lapwings for breeding on islands (Fig. 4). This is in accordance with our expectations, as birds on islands are free from disturbance by visitors and have excellent access to water due to the gentle slope of the islands' edges. Similarly, preference for use of artificially created islands was also found for other wading species elsewhere (Bakker and Piersma 2006, Golder et al. 2008, Scarton et al. 2012). Out of 75 small islands in the study area during the study period, $68(91 \%)$ were occupied at least once during our 2-year study. However, probably as a result of territoriality found in tropical lapwings (e. g., Walters 1979, 1990, del Hoyo et al. 1996, Brown and Brown 2004), the vast majority of islands were occupied by just one pair for the whole breeding season. Therefore, additional analysis of island properties could help us understand the features that may increase the attractiveness of the remaining unoccupied islands for breeding lapwings.

Surprisingly, we found no clear pattern of avoidance to breeding close to roads (Fig. 4) where the greatest disturbance was expected. This pattern might be explained by the strong preference for vicinity to water, as most lapwings obviously preferred to breed close to water even away from the islands (Fig. 3), where most roads are also concentrated. It is noteworthy that we found 44 nests (i.e., 12\%) less than $2 \mathrm{~m}$ from the road (Append. 3), and most of them hatched successfully. The lapwings were thus obviously highly resistant to anthropogenic disturbance of cars and people on the roads. Bird eggs in the desert need almost continuous care from parents especially during the hottest parts of the day, as even few minutes' exposure of eggs to sun might 
negatively affect embryo development (Cooper et al. 2005). In this context, some nests were placed in the shade of the trees (at least for a certain part of the day), which is somewhat atypical for lapwings (del Hoyo et al. 1996). In fact, many shorebirds including lapwings breed mostly in open areas where they are exposed to direct sunlight (Append. 2), but are able to better detect predators, thereby reducing predation risk (Grant 1982, Maclean 1984, Amat and Masero 2004b). Placing nests in the shade of trees can help to deal with stressful thermal conditions (Grant 1982, Brown and Downs 2003, Amat and Masero 2004a), which may present an adaptation of the lapwings to a hot climate with a potential trade-off between the risks of egg predation and egg overheating during forced incubation breaks. However, the costs and benefits arising from such nest placement need further investigation.

The breeding season of the lapwing in the study area (Append. 3 ) is longer than that reported elsewhere within the distribution range of this species (April to June; Khalil et al. 2019, Muralidhar and Barve 2013). As this lapwing can lay replacement clutches and use multiple brooding (del Hoyo et al. 1996), the long breeding season in combination with permanent water availability and favorable breeding conditions on islands can substantially enhance the total reproductive success of the population.

\section{Breeding Success and Chick Productivity}

According to our expectations, nest predation as well as total nest failure rates on islands were ca. four times lower than on the mainland (Tables 2 and 3). A lower predation rate on islands suggests that the birds breeding on islands were better protected, probably mainly from mammalian predators such as Red fox (Vulpes vulpes), which seem to be major predators of lapwing nests at least in the temperate zone (Macdonald and Bolton 2008, Brynychová et al. 2020), and from Desert Monitor (Varanus griseus), a predator of ground-nesting birds and their nests elsewhere on the Arabian Peninsula (Stanner and Mendelssohn 1986). Both these predators are common and may be important predators also at our study area. Therefore, the Reserve management carried out a mesocarnivore control program to eliminate at least foxes and feral cats (personal communication) and their possible impact on breeding birds.

The predators remained mostly unidentified in our study area. On the basis of the observed tracks, we also assumed a significant role for bird predators, such as Western Marsh Harrier (Circus aeruginosus), Brown-necked Raven (Corvus ruficollis), Great Grey Shrike (Lanius excubitor), and Common Myna (Acridotheres tristis), perching in the trees and shrubs (Kumar et al. 2020; personal observations). A predation event by a female Pallid Harrier (Circus macrourus) on an adult lapwing (personal observations) may suggest predation by the Pallid Harrier on chicks as well. Even though predation is a major cause of nest and chick mortality in ground-nesting birds (Gómez-Serrano and López-López 2014, Teunissen et al. 2008), it is difficult to quantify the importance of a particular predator species (Mason et al. 2018). However, despite this uncertainty in the overview of the main nest predators in the area, we assume that the presence of a number of potential bird predators opens up the opportunity for incidental predation by birds, particularly if the nest is not guarded by the parent (Bocz et al. 2017). As well, the disturbance of ground-nesting birds by human visitors in the mainland and particularly along lake coasts and roads can be an important side effect. Because birds often get off the nest when humans walk by, we can speculate that unguarded nests may be more prone to predation (Smith et al. 2012). However, whether reducing disturbance and increasing hiding places along the lake shorelines (such as sparse reeds) would reduce the predation risk by avian predators on both lapwing nests and chicks awaits future evaluation.

Chicks from island nests tended to have lower initial body condition and slower growth, although the growth rate was largely variable among chicks (Fig. 5b, Table 5). Therefore, we can speculate that, although the islands are safer for nesting, they provide less food for chicks. This would correspond to the fact that we frequently observed the chicks from island nests foraging on mainland. The lapwings were probably forced to leave safer islands and visit the mainland coast of lakes to forage. Low food availability on islands, together with the energy costs of repeated movements from the island to the mainland (crossing the water by swimming $10-30 \mathrm{~m}$ ) and back, may have contributed to slower growth of chicks hatched on islands. The presence of chicks from safer islands on the mainland may also be the cause of similar survival rates of chicks from islands and mainland.

Frequent breeding along lake shores as well as occurrence of island chicks on the mainland pose a conservation issue, i.e., how to increase food availability on the islands as well as reduce the access of visitors to the immediate coastlines of the lakes and minimize disturbances of birds there. Although we don't have direct evidence that human disturbance causes the increase in nest predation, or reduces chick survival, we regularly observed how human visitors approaching the chicks increased adult alarming and reduced foraging time available for the chicks, who remain hidden for the duration of adult alarming (Khalil et al. 2019). This may result in increased stress, starvation, and/or predation risk for the chicks (Sharpe et al. 2009). Low green fences have recently been set up around the lakes to separate coasts from the roads and to reduce the access of visitors to the lake shores. Additionally, we suggest creating other "visitor-free" zones on the mainland, including reed beds, which would not restrict the visitors' space much, but would provide calm foraging places and shelter for chicks.

\section{CONCLUSION}

We have shown the importance of a large system of water reservoirs in a vast desert to breeding shorebirds, even without direct connection to other similar wetland habitats. The artificial lake system in Al Marmoom Desert Conservation Reserve in Dubai Emirate was designed for recreational purposes but also supports a dense population of Red-wattled Lapwings. The area provides year-round accessible freshwater lakes, where the potential for placing nests close to water for their long breeding season is probably the key reason for its attractiveness for Redwattled Lapwings (and other bird species) and their successful reproduction. Islands of most lakes represent a safer alternative for breeding nearby water than mainland habitats around the lakes. Frequent use of disturbed coastlines near roads by lapwings calls for additional conservation measures, but real benefits and the feasibility of these measures require further research.

As far as we know, this is the first study focused in detail on the habitat choice and the breeding attributes of the Red-wattled 
Lapwing in desert conditions. In particular, we have demonstrated that a sufficiently large desert lakes system with stable water reservoirs, properly designed shores, and islands can serve as a refuge for a breeding population of a shorebird species tightly tied to the water environment, and that this kind of system can boost biodiversity. We have confirmed that the creation of recreational zones with lakes in the Arabian desert may significantly increase the carrying capacity of the areas for breeding shorebirds, despite permanent disturbance from human visitors.

\section{AUTHOR CONTRIBUTIONS}

E. E. and M. Š . conceived the study, and all authors contributed to the preparation of logistics and field data collection during 2 years of study. Also, all authors contributed to the data collection. Data analysis was done by M. S., M. S., and P. C., and E. E., M. S., and M. S. wrote the manuscript with input from the other authors.

Responses to this article can be read online at: https://www.ace-eco.org/issues/responses.php/1978

\section{Acknowledgments:}

We are grateful to Dubai Municipality for access to the study area and field work facilitation. We thank Mr. Robin Healey for his kind language assistance and $\mathrm{Mr}$. Nadeem for kind help with map drawing. We are grateful to anonymous reviewers for their valuable comments. This work was funded by IGA FŽP (20184221) and IGA (2020B0028_a) from the Czech University of Life Sciences, Prague and by TAČR ZÉTA 2 (TJ02000199).

\section{LITERATURE CITED}

Aebischer, N. J. 1999. Multi-way comparisons and generalized linear models of nest success: extensions of the Mayfield method. Bird Study 46 (Suppl.):S22-S31. https://doi.org/10.1080/00063659909477228

Almond, R. E. A., M. Grooten, and T. Petersen, editors. 2020. Living planet report 2020 - bending the curve of biodiversity loss. World Wildlife Federations (WWF), Gland, Switzerland.

Amano, T., T. Székely, B. Sandel, S. Nagy, T. Mundkur, T. Langendoen, D. Blanco, C. U. Soykan, and W. J. Sutherland. 2018. Successful conservation of global waterbird populations depends on effective governance. Nature 553:199-202. https://doi. org/10.1038/nature25139

Amat, J. A., and J. A. Masero. 2004a. How Kentish plovers, Charadrius alexandrinus, cope with heat stress during incubation. Behavioral Ecology and Sociobiology 56:26-33. https://doi. org/10.1007/s00265-004-0758-9

Amat, J. A., and J. A. Masero. 2004b. Predation risk on incubating adults constrains the choice of thermally favourable nest sites in a plover. Animal Behaviour 67:293-300. https://doi.org/10.1016/ j.anbehav.2003.06.014
Amat, J. A., and J. A. Masero. 2007. The functions of bellysoaking in Kentish Plovers Charadrius alexandrinus. Ibis 149:91-97. https://doi.org/:10.1111/j.1474-919X.2006.00615.x

Andersson, E., S. Brogaard and L. Olsson. 2011. The political ecology of land degradation. Annual Review of Environment and Resources 36:295-319. https://doi.org/10.1146/annurevenviron-033110-092827

Bakker, J. P., and T. Piersma. 2006. Restoration of intertidal flats and tidal salt marshes. Pages 174-192 in J. van den Andel and J. Aronson, editors. Restoration ecology. Blackwell Publishing, Singapore.

Bates, D., M. Maechler, B. Bolker, and S. Walker. 2015. Fitting linear mixed-effects models using lme4. Journal of Statistical Software 67:1-48. https://doi.org/10.18637/jss.v067.i01

Baumann, N. 2006. Ground-nesting birds on green roofs in Switzerland: preliminary observations. Urban Habitats 4:37-50.

Birdlife International. 2009. Bird species decline: wader populations decline faster than ever. Science Daily. Science Daily, 9 June 2009. [online] URL: www.sciencedaily.com/ releases/2009/06/090606195747.htm|

Bocz, R., D. Szep, D. Witz, L. Ronczyk, K. Kurucz, J. J. Purger. 2017. Human disturbances and predation on artificial ground nests across an urban gradient. Animal Biodiversity and Conservation 40:153-157. https://doi.org/10.32800/abc.2017.40.0153

Brown, M., and C. T. Downs. 2003. The role of shading behaviour in the thermoregulation of breeding crowned plovers (Vanellus coronatus). Journal of Thermal Biology 28:51-58. https://doi. org/10.1016/S0306-4565(02)00036-0

Brown, G., and B. Böer. 2004. Interpretation manual of the major terrestrial natural and semi-natural habitat types of Abu Dhabi Emirate. Internal Research Report. Environmental Research and Wildlife Development Agency (ERWDA), Abu Dhabi, United Arab Emirates.

Brown, M., and K. Brown. 2004. Nest defence in Crowned Lapwings (Vanellus coronatus) - influences of nesting stage and ambient temperature. Ostrich 75:162-164. https://doi. org/10.2989/00306520409485429

Brynychová, K., M. Šálek, E. Vozabulová, and M. Sládeček. 2020. Daily rhythms of female self-maintenance correlate with predation risk and male nest attendance in a biparental wader. Journal of Biological Rhythms 35:489-500. https://doi. org/10.1177/0748730420940465

Burfield, I. J., J. Westrip, R. D. Sheldon, C. Hermes, H. Wheatley, D. Smith, K. A. Harding and D. J. Allen. 2021. UAE national red list of birds. Ministry of Climate Change and Environment, Dubai, United Arab Emirates.

Büttger, H., S. Thyen, and K.-M. Exo. 2006. Nest-site selection, predation and hatching success of Redshanks Tringa totanus breeding on Wangerooge Island. Vogelwarte 44:123-130.

Campbell, O., and T. Pedersen. 2011. Birding the United Arab Emirates. Birding World 24(4):160-176.

Campbell, O., and M. Smiles. 2019. Notable breeding records from a recently established anthropogenic, agricultural site in the United Arab Emirates. Sandgrouse 41(1):18-31. 
Clark, R. G., and D. Shutler. 1999. Avian habitat selection pattern from process in nest site use by ducks. Ecology 80:272-287. https:// doi.org/10.1890/0012-9658(1999)080[0272:AHSPFP]2.0.CO;2

Cooper, C. B., W. M. Hochachka, G. Butcher, and A. A. Dhondt. 2005. Seasonal and latitudinal trends in clutch size: thermal constraints during laying and incubation. Ecology 86:2018-2031. https://doi.org/10.1890/03-8028

Cramp, S., and K. E. L. Simmons. 1983. The birds of the Western Palearctic. Vol. 3. Waders to gulls. Oxford University Press, Oxford, UK.

del Hoyo, J., A. Elliott, and J. Sargatal. 1996. Handbook of the birds of the world. Vol. 3. Hoatzin to Auks. Lynx Edicions, Barcelona, Spain.

Delany, S., D. Scott, T. Dodman, and D. Stroud. 2009. An atlas of wader populations in Africa and Western Eurasia. Wetlands International, London, UK.

Dubai Municipality. 2017. Bird ringing within the Emirate of Dubai. Annual Report, Natural Resources Conservation Section, Environment Department, Dubai Municipality, Dubai.

Dubai Municipality. 2018. Al Marmoom Desert Conservation Management Plan. 2018-2023.Version1. 12. Natural Resources Conservation Section, Environment Department, Dubai Municipality, Dubai.

Dubai Municipality. 2019a. Environment management plans (EMP) for seven designated protected and surrounding areas in the emirate of Dubai. Final environmental baseline study (EBS) and metadata report. Internal report. Dubai Municipality, Dubai.

Dubai Municipality. 2019b. Human impacts on lakes and associated species in Al Marmoom Desert Conservation Report. Annual report. Natural Resources Conservation Section, Environment Department, Dubai Municipality, Dubai.

eBird. 2021. eBird: an online database of bird distribution and abundance [web application]. eBird, Cornell Lab of Ornithology, Ithaca, New York, New York, USA. [online] URL: http://www. ebird.org.

Eck, S., J. Fiebig, W. Fiedler, I. Heynen, B. Nicolai, T. Töpfer, and F. Woog. 2011. Measuring birds/Vögel Vermessen. Deutsche Ornithologen-Gesellschaft, Minden, Germany.

Gelman, A., and J. Hill. 2007. Data analysis using regression and multi-level/hierarchical models. Cambridge University Press, New York, New York, USA and Cambridge, UK.

Gelman A., Y.-S. Su, M. Yajima, J. Hill, M. Pittau, J. Kerman, T. Zheng, and D. Vincent. 2016. Data analysis using regression and multilevel/hierarchical models. Comprehensive R Archive Network (CRAN) Repository, 1-53. https://doi.org/10.1017/ CBO9780511790942

Golder, W., D. Allen, S. Cameron, and T. Wilder. 2008. Dredged material as a tool for management of Tern and Skimmer nesting habitats. Dredging Operations and Environmental Research (DOER) Technical Notes Collection (ERDC TN-DOER-E24). U.S. Army Engineer Research and Development Center, Vicksburg, Mississippi, USA.
Gómez-Serrano, M. A., and P. López-López. 2014. Nest site selection by Kentish Plover suggests a trade-off between nestcrypsis and predator detection strategies. PLOS ONE 9: e107121. https://doi:10.1371/journal.pone.0107121

Grant, G. S. 1982. Avian incubation: egg temperature, nest humidity, and behavioural thermoregulation in a hot environment. Ornithological Monographs 30:1-75. https://doi. org/10.2307/40166669

Hartman, C. A., and L. W. Oring. 2009. Reproductive success of long-billed curlews (Numenius americanus) in northeastern Nevada hay fields. Auk 126;420-430. https://doi.org/10.1525/ auk.2009.08062

Hildén, O. 1965. Habitat selection in birds: a review. Annales Zoologici Fennici 2:53-75.

Hox, J., M. Moerbeek, and R. van de Schoot. 2018. Multilevel analysis: techniques and applications, Third edition (Quantitative Methodology Series). Routledge. New York, New York, USA. https://doi.org/10.4324/9781315650982

Jackson, H., and S. D. Prince. 2016. Degradation of net primary production in a semiarid rangeland. Biogeosciences 13:4721-4734. https://doi.org/10.5194/bg-13-4721-2016

Kalsi, R. S., and S. Khera. 1986. Some observations of breeding and displacement behaviour of Red-wattled Lapwing Vanellus indicus. Research Bulletin (Science) of the Panjab University 37:134-141.

Khalil, S., T. Hussain, M. Anwar, M. Rafay, M. Abdullah, M. Khalid, M. Tariq, S. Sarwar, R. Tabish, and I. Ashraf. 2019. Breeding biology of red wattled lapwing (Vanellus indicus) from Southern Punjab, Pakistan. Biodiversity and Conservation 11:78-84. https://doi.org/10.5897/IJBC2018.1197

Komuscu, A. U. 2017. Long-term mean monthly temperatures trends of the United Arab Emirates. International Journal of Global Warming 11:1-22. https://doi.org/10.1504/IJGW.2017.10001875

Köster, H., G. T. Nehls, and K. M. Thomsen. 2001. Hat der Kiebitz noch eine Chance? Untersuchungen $\mathrm{zu}$ den Rückgangsursachen des Kiebitzes (Vanellus vanellus) in Schleswig-Holstein. Corax 18:121-132.

Krebs, C. J. 1999. Ecological methodology. Second edition. Addison Wesley Longman, Menlo Park, California, USA.

Kumar, C., S. K. Thind, Joshua, and A. S. Kaleka. 2020. breeding behaviour of red-wattled lapwing, Vanellus indicus Boddaert, 1783) in agricultural landscape of Punjab. Uttar Pradesh Journal of Zoology 41(8):27-51. Retrieved from https://mbimph.com/ index.php/UPJOZ/article/view/1544

Laidlaw, R. A., J. Smart, M. A. Smart, and J. A. Gill. 2017. Scenarios of habitat management options to reduce predator impacts on nesting waders. Journal of Applied Ecology 54:1219-1229. https://doi.org/10.1111/1365-2664.12838

Ma, Z., Y. Cai, B. Li, and J. Chen. 2010. Managing wetland habitats for waterbirds: an international perspective. Wetlands 30:15-27. https://doi.org/10.1007/s13157-009-0001-6 
Macdonald, M. A., and M. Bolton. 2008. Predation on wader nests in Europe. Ibis 150 (Suppl. 1):54-73. https://doi.org/10.1111/ j.1474-919X.2008.00869.x

Maclean, G. L. 1984. Arid-zone adaptations of waders (Aves: Charadrii). South African Journal of Zoology 19:78-81. https:// doi.org/10.1080/02541858.1984.11447861

Martin, T. E., and J. J. Roper. 1988. Nest predation and nest-site selection of a western population of the Hermit Thrush. Condor 90:51-57. https://doi.org/10.2307/1368432

Mason, L. R., J. Smart, and A. L. Drewitt. 2018. Tracking day and night provides insights into the relative importance of different wader chick predators. Ibis 160:71-88. https://doi. org/10.1111/ibi.12523

Mayfield, H. F. 1975. Suggestions for calculating nest success. Wilson Bulletin 87:456- 466

McGrady, M. J., W. Al Fazari, M. Al Jahdhami, M. Fisher, A. Y. Kwarteng, H. Walter, and M. K. Oli. 2019. Island accessibility and distance from beach influence nesting success of Sooty Falcons Falco concolor in Oman. Ibis 161:162-171. https://doi. org/10.1111/ibi.12601

McIntyre, A. F., and J. A. Heath. 2011. Evaluating the effects of foraging habitat restoration on shorebird reproduction: the importance of performance criteria and comparative design. Journal of Coastal Conservation 15:151-157. https://doi. org/10.1007/s11852-010-0128-X

Munro, B. Y. M. 2017. What's killing the world's shorebirds? Nature 541:16-20. https://doi.org/10.1038/541016a

Muralidhar, A., and S. Barve. 2013. Peculiar choice of nesting of Red-wattled Lapwing Vanellus indicus in an urban area in Mumbai, Maharashtra. Indian Birds 8:6-9.

Narwade, S., M. Fartade, and K. Fartade. 2010. Effect of agricultural activities on breeding success of Red-wattled Lapwing Vanellus indicus. National Journal of Life Sciences, India $7: 31-34$.

Narwade, S., M. Fartade, and K. Fartade. 2011. Nesting ecology of Red-wattled Lapwing in agricultural landscape. Life Science Bulletin, India 8:97-100.

R Core Team. 2020. R: a language and environment for statistical computing. R Foundation for Statistical Computing, Vienna, Austria. [online] URL: https://www.R-project.org/

Rodrigues, V. B., F. M. Jesus., and R. I. Campos. 2018. Local habitat disturbance increases bird nest predation in the Brazilian Atlantic rainforest. Animal Biodiversity and Conservation 41 (1):117-120. https://doi.org/10.32800/abc.2018.41.0117

Roodbergen, M., B. van der Werf and H. Hötker. 2012. Revealing the contributions of reproduction and survival to the Europewide decline in meadow birds: review and meta-analysis. Journal of Ornithology 153:53-74. https://doi.org/10.1007/s10336-011-0733$\mathrm{y}$

Saalfeld, S. T., B. L. Hill, and R. B. Lanctot. 2013. Shorebird responses to construction and operation of a landfill on the Arctic coastal plain. Condor 115:816-829. https://doi.org/10.1525/ cond.2013.120169
Scarton, F., G. Cecconi, and R. Valle. 2012. Use of dredge islands by a declining European shorebird, the Kentish Plover Charadrius alexandrinus. Wetlands Ecology and Management (2013) 21:15-27. https://doi.org/10.1007/s11273-012-9276-0

Sharpe, F., M. Bolton., R. Sheldon, and N. Ratcliffe. 2009. Effects of color banding, radio tagging, and repeated handling on the condition and survival of Lapwing chicks and consequences for estimates of breeding productivity. Journal of Field Ornithology 80:101-110. https://doi.org/10.1111/j.1557-9263.2009.00211.x

Sharps, E., J. Smart, L. R. Mason, K. Jones, M. W. Skov, A. Garbutt, and J. G. Hiddink. 2017. Nest trampling and ground nesting birds: quantifying temporal and spatial overlap between cattle activity and breeding redshank. Ecology and Evolution 7:6622-6633. https://doi.org/10.1002/ece3.3271

Smith, P. A., H. G. Gilchrist, and J. N. M. Smith. 2007. Effects of nest habitat, food, and parental behavior on shorebird nest success. Condor 109:15-31. https://doi.org/10.1093/condor/109.1.15

Smith, P. A., I. Tulp, H. Schekkerman, H. G. Gilchrist, and M. R. Forbes. 2012. Shorebird incubation behaviour and its influence on the risk of nest predation. Animal Behaviour 84:835-842. https://doi.org/10.1016/j.anbehav.2012.07.004

Specht, H., V. St.-Louis, C. L. Gratto-Trevor, N. Koper, C. G. Skaggs, T. A. Ronningen, and W. Todd. 2020. Habitat selection and nest survival in two Great Plains shorebirds. Avian Conservation and Ecology 15(1): 3. https://doi.org/10.5751/ ACE-01487-150103

Spinoni, J., J. Vogt, G. Naumann, H. Carrao, and P. Barbosa. 2015. Towards identifying areas at climatological risk of desertification using the Koppen-Geiger classification and FAO aridity index. International Journal of Climatology 35:2210-2222. https://doi.org/10.1002/joc.4124

Stanner, M., and H. Mendelssohn. 1986. The diet of Varanus griseus in the southern coastal plain of Israel (Reptilia: Sauria). Israel Journal of Zoology 34(1-2):67-75. https://www.tandfonline. com/doi/abs/10.1080/00212210.1986.10688586

Stewart-Smith, J. 1977. Waders in the United Arab Emirates part 1. Emirates Natural History Group, Bulletin 1. [online] URL: http://enhg.org/bulletin/b01/01_07.htm

Studds, C. E., B. E. Kendall, N. J. Murray, H. B. Wilson, D. I. Rogers, R. S. Clemens, K. Gosbell, C. J. Hassell, R. Jessop, D. S. Melville, D. A. Milton, D. T. Minto, H. P. Possingham, A. C. Riegen, P. Straw, E. J. Woehler, and R. A. Fuller. 2017. Rapid population decline in migratory shorebirds relying on Yellow Sea tidal mudflats a stopover site. Nature Communications 8: 14895. https://doi.org/10.1038/ncomms14895

Teunissen, W., H. Schekkerman, F. Willems, and F. Majoor. 2008. Identifying predators of eggs and chicks of Lapwing Vanellus vanellus and Black-tailed Godwit Limosa limosa in the Netherlands and the importance of predation on wader reproductive output. Ibis 150:74-85. https://doi.org/10.1111/ j.1474-919X.2008.00861.X

Toral, G. M., and J. Figuerola. 2012. Nest success of Black-winged Stilt Himantopus himantopus and Kentish Plover Charadrius alexandrinus in rice fields, southwest Spain. Ardea 100:29-36. https://doi.org/10.5253/078.100.0106 
Thyen, S., and K. M. Exo. 2005. Interactive effects of time and vegetation on reproduction of redshanks (Tringa totanus) breeding in Wadden Sea salt marshes. Journal of Ornithology 146:215-225. https://doi.org/10.1007/s10336-005-0082-9

van Horne, B. 1983. Density as a misleading indicator of habitat quality. Journal of Wildlife Management 47:893-901. https://doi. org/10.2307/3808148

van Paassen, A. G., D. H. Veldman, and A. J. Beintema. 1984. A simple device for determination of incubation stages in eggs. Wildfowl 35:173-178.

Walters, J. 1979. Interspecific aggressive behaviour by long-toed lapwings (Vanellus crassirostris). Animal Behaviour 27:969-981. https://doi.org/10.1016/0003-3472(79)90045-9

Walters, J. R. 1990. Anti-predatory behavior of lapwings: field evidence of discriminative abilities. The Wilson Bulletin 102 (1):49-70.

Wiersma, P., and G. M. Kirwan. 2020. Red-wattled Lapwing (Vanellus indicus), version 1.0. In J. del Hoyo, A. Elliott, J. Sargatal, D. A. Christie, and E. de Juana, editors. Birds of the world.Cornell Lab of Ornithology, Ithaca, New York, USA. https://doi.org/10.2173/bow.rewlap1.01

Zöckler, C., S. Delany, and W. Hagemeijer. 2003. Wader populations are declining - how will we elucidate the reasons? Wader Study Group Bullutin 100:202-211. 
APPENDIX 1. The population size of Red-wattled Lapwing in the study area in Al Marmoom Reserve in 2019.

Total census in breeding season 2019

Total number of recoded adults

Number of unmarked adults

Number of marked adults

Number of marked and identified adults

Number of marked and repeatedly recorded adults

Number of present but not recorded marked adults
Co- Ma- June Remark/Legend

de rch

219285 Sum of all un/marked

adults regardless of

whether they were

repeatedly recorded or

not during the census

UN 151155 Sum of unmarked adults

regardless of whether

they were repeatedly

recorded or not during

the census

MA $68 \quad 109$ Sum of marked adults

regardless of whether

they were repeatedly

recorded or not during

the census

MI $63 \quad 81 \quad$ Sum of marked and

individually recognized

adults regardless of

whether they were

repeatedly recorded or

not during census

RE $11 \quad 18 \quad$ Sum of marked and

individually recognized

adults repeatedly

recorded during census

$\begin{array}{llll}\text { PR } & 37 & 30 & \text { Marked adults not }\end{array}$

recorded during the

census but expected to

be present (i.e.

overlooked adults, as a

permanent population is

expected)

S- 244247

UM

The formula used to

calculate population size

$\mathrm{SUM}=(\mathrm{MA}+\mathrm{UN})^{*}$

$\mathrm{idx}^{*} \mathrm{Zv}$, where idx $=$

$(\mathrm{MI}-\mathrm{RE}) / \mathrm{MI}$ and $\mathrm{Zv}=$

(MI-RE+ PR)/MI 
APPENDIX 2. A nest of the Red-wattled Lapwing with complete clutch on bare ground of sand dune nearby road and lake.

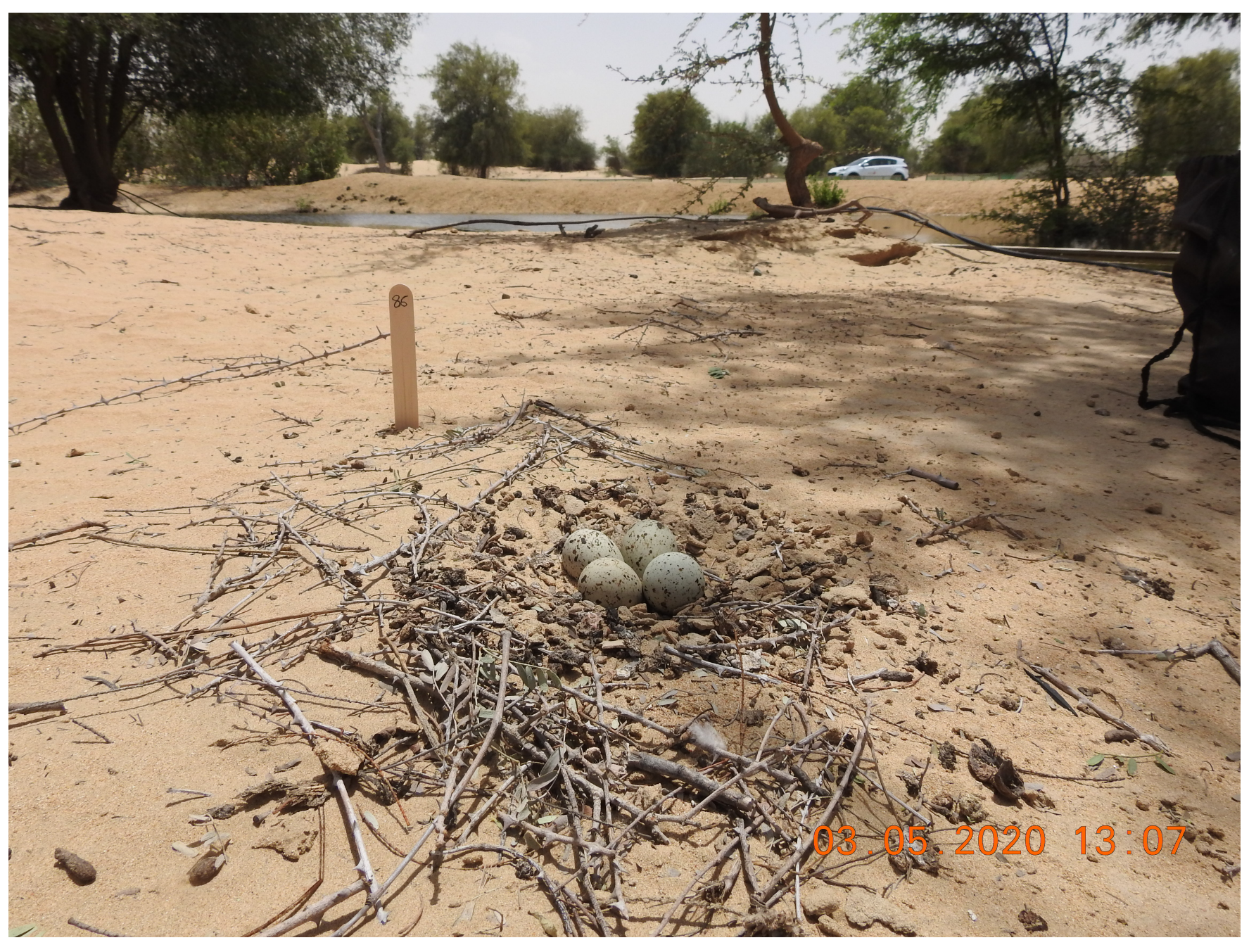


APPENDIX 3. A nest of the Red-wattled Lapwing with visibly incubating adult on bare ground of sand dune in the immediate vicinity of the road monitored by camera (red circle).

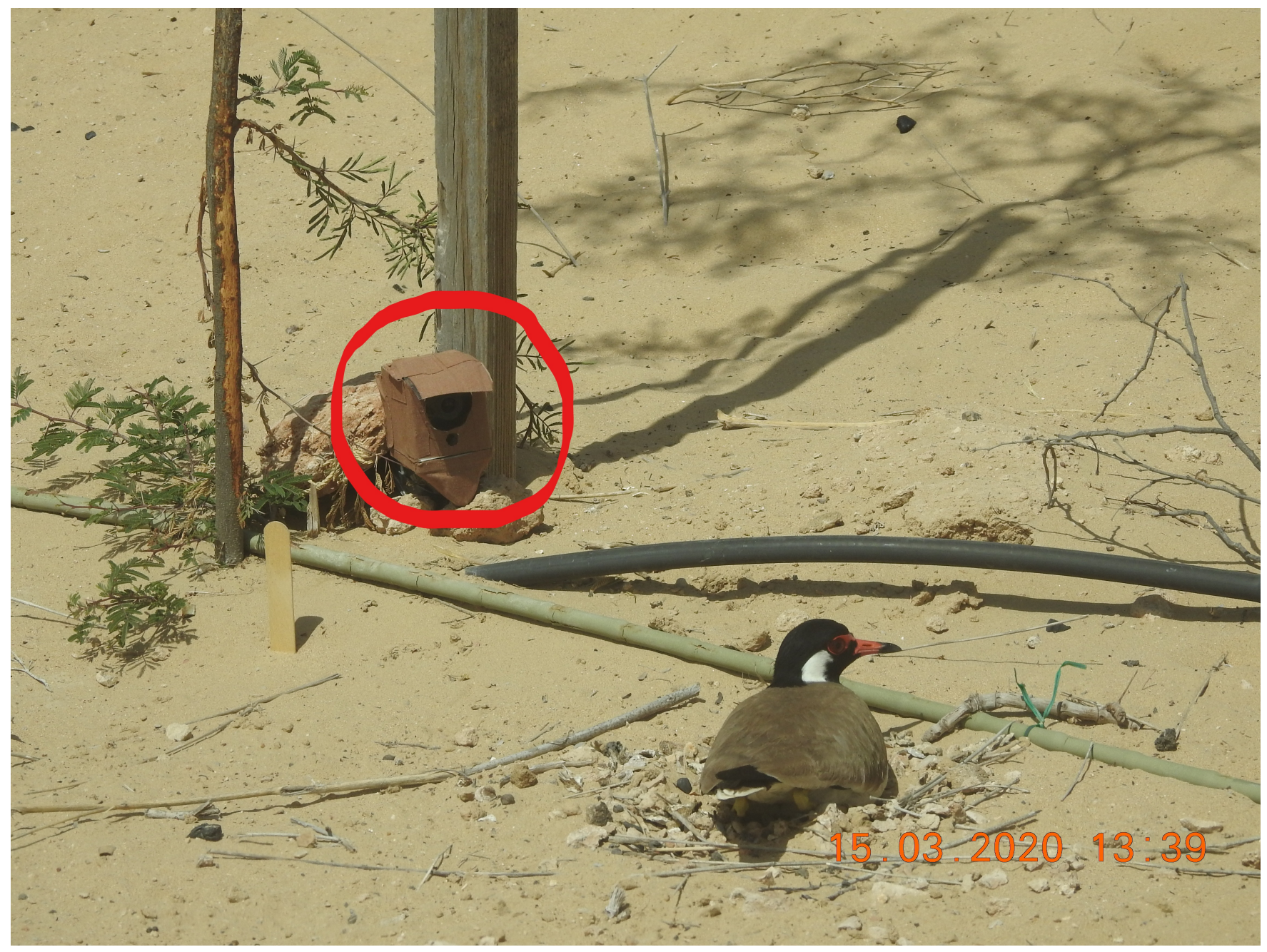


APPENDIX 4. Red-wattled Lapwing nesting progress among varied habitats during 2018 and 2019; the numbers on the $x$-axis represent the order of the day in the year (i.e., $20=$ January 20, $40=$ February 9 etc.).

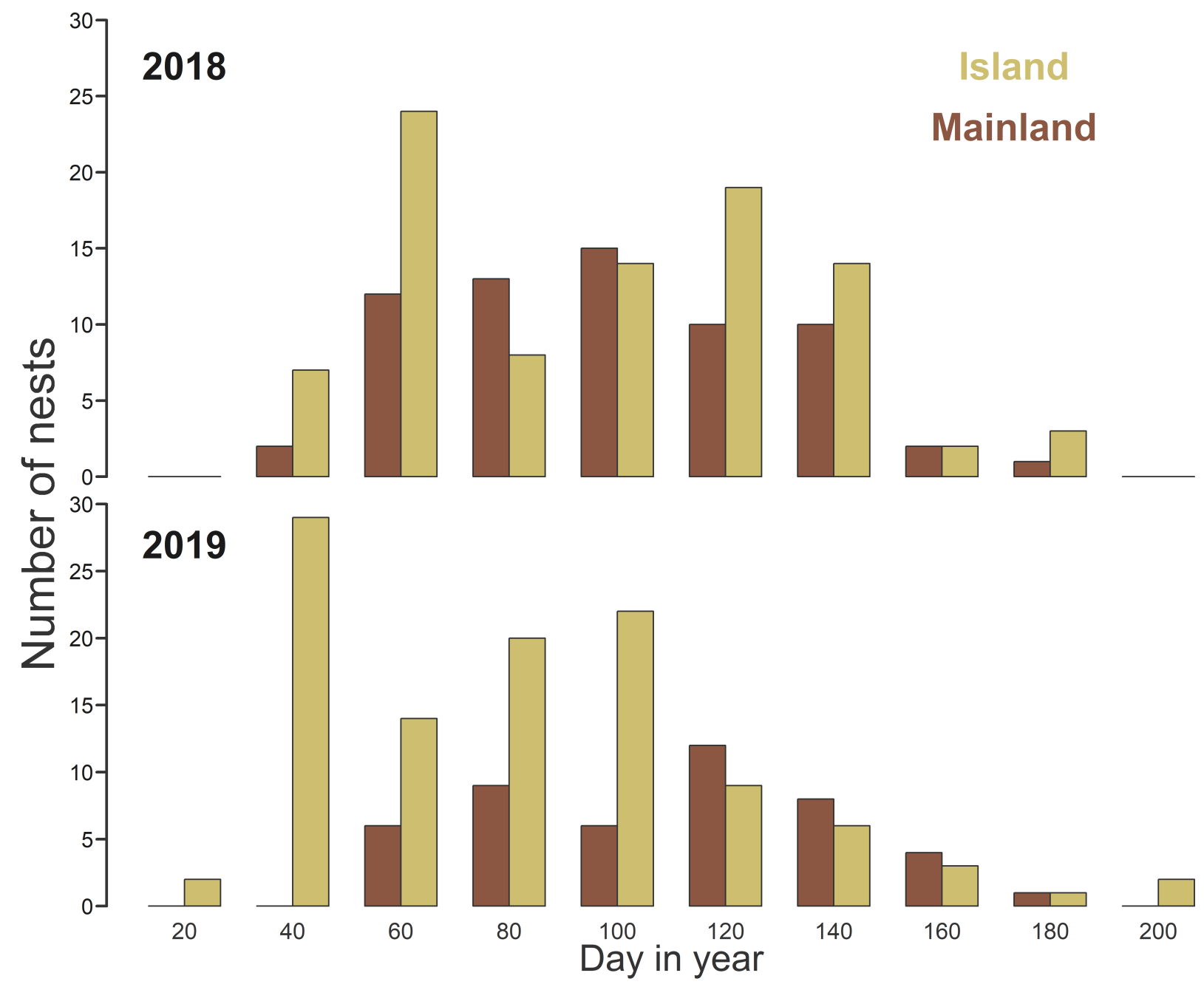


Avian Conservation and Ecology 16(2): 20

http://www.ace-eco.org/vol16/iss2/art20/

APPENDIX 5. The fates (\%) of Red-wattled Lapwing nests in the Al Marmoom Reserve in 2018 and 2019

$\begin{array}{llllll}\text { Year } & \text { Hatched } & \text { Depredated } & \text { Failed } & \text { Unknown } & \text { Total nests } \\ 2018 & 66 \% & 12 \% & 5 \% & 16 \% & 187 \\ 2019 & 60 \% & 19 \% & 10 \% & 11 \% & 174\end{array}$


APPENDIX 6. Proportion of lapwing nests in various habitats and in relation to distance from water and road. Median distance between nest and nearest water (a) and between nest and nearest road (b), and the proportion of nests identified within a particular habitat (c-f; see Fig. 3) for the beginning, the middle and the end of the season (for details, see Methods). Boxplots represent the distributions of the medians obtained by running 1,000 random simulations (for details, see Methods). Box depict the median (horizontal line inside the box), the 25 th to 75 th percentiles (box), the 25 th and 75 th percentiles minus or plus the $1.5 \times$ interquartile range, respectively, or the minimum and maximum value, whichever is smaller (whiskers), and outliers (circles). Triangles and squares represent the medians or the proportions found for real nests active on a particular date and year, respectively
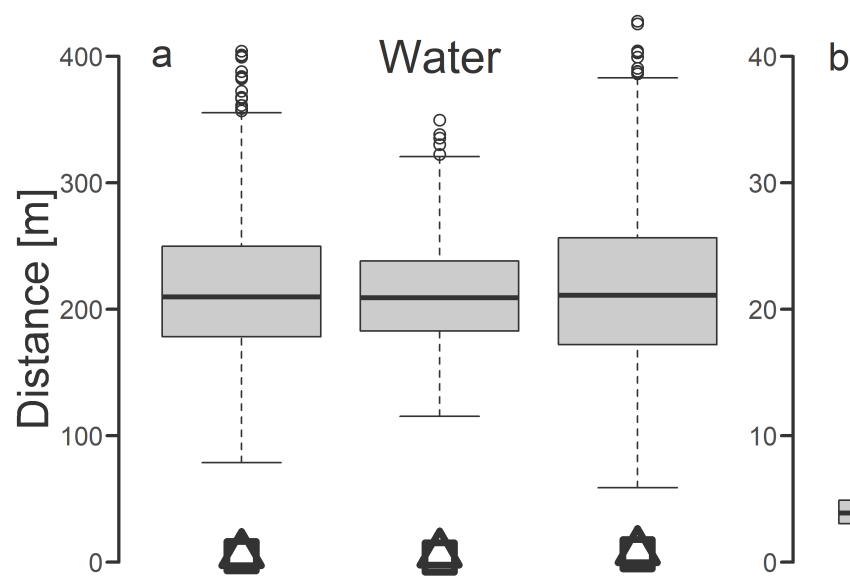

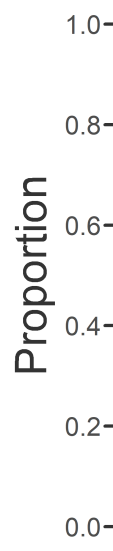

C

c

\section{Islands}
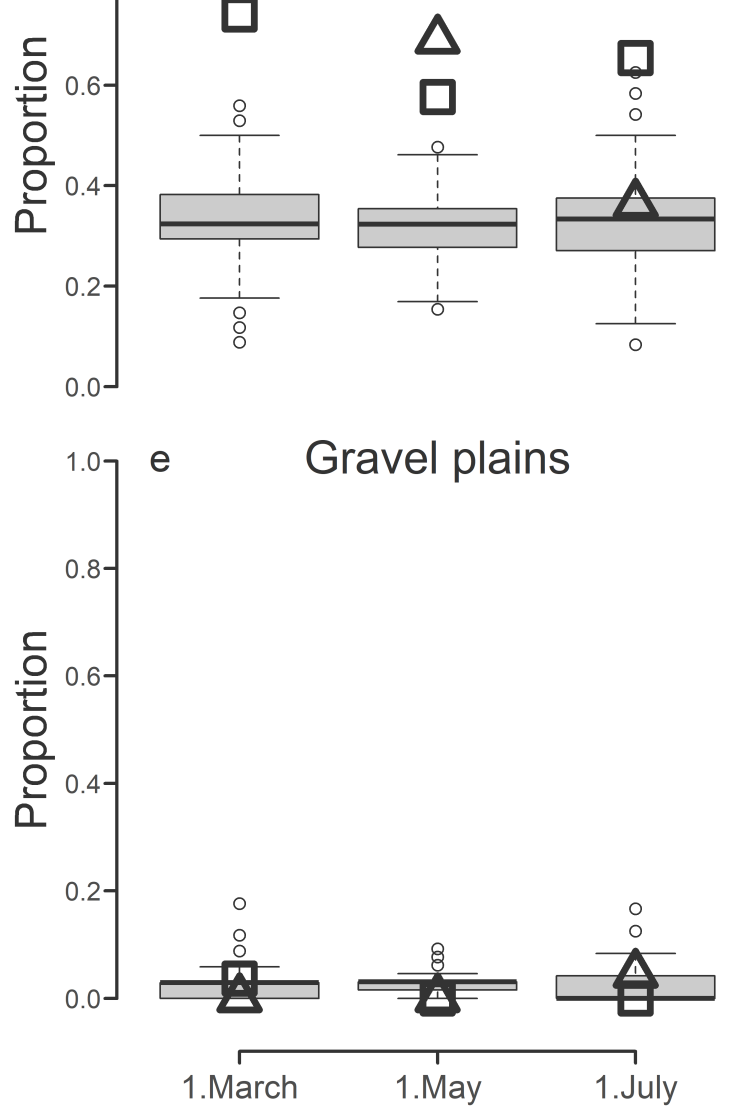

b

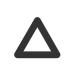

Road

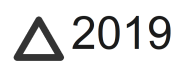

$\square 2018$

d

Plantations
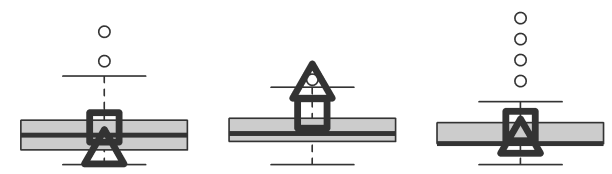

f

\section{Sand dunes}
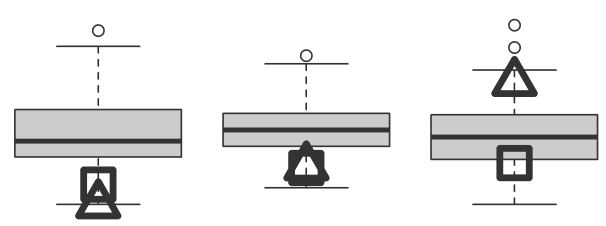

1.May

1.July 